\title{
Effects of remote virtual work environment during COVID-19 pandemic on technostress among Menoufia University Staff, Egypt: a cross-sectional study
}

\author{
Hala Marawan Gabr ${ }^{1}$. Shaimaa Sherif Soliman ${ }^{1} \cdot$ Heba Khodary Allam $^{1}$ (D) $\cdot$ Shaimaa Yaihya Abdel Raouf ${ }^{1}$
}

Received: 23 March 2021 / Accepted: 21 May 2021 / Published online: 25 May 2021

(C) The Author(s), under exclusive licence to Springer-Verlag GmbH Germany, part of Springer Nature 2021

\begin{abstract}
Technostress during the COVID-19 pandemic has become more prevalent as a result of the global preventive measures applied to limit the spread of infection. These measures included remote working from home in both public and private organizations. The objective of this study is to study technostress and challenges of remote virtual work environment among university staff members at Menoufia University, Egypt. A cross-sectional study was conducted over Menoufia University academic staff members in Egypt. The participants were chosen from both practical and theoretical colleges in Menoufia University using a multistage random sample. Tarfadar technostress questionnaire was used. Cortisol blood level was measured for all participants. This study included 142 participants. The mean age of the group was $36.32 \pm 6.41$ years. 52.1 percent worked in practical colleges, and $60.6 \%$ were lecturers or higher. Their mean cortisol level was $15.61 \pm 7.07 \mathrm{mcg} / \mathrm{dl}$. Participants who were females, reside in rural areas, held a lecturer or higher position, had poor work-environment $\mathrm{WiFi}$, and lacked technical training had significantly higher levels of technostress subscales. Most of the technostress subscales were significantly correlated with age and blood cortisol levels. The predictors of work overload in multivariate regression were female gender and a work environment with poor WiFi. Female gender, theoretical colleges, being lecturer or higher, and poor WiFi were the predictors for invasion. Among university staff members, technostress was found to be evident. High levels of technostress were significantly influenced by age, higher professions, female gender, and a bad workplace environment.
\end{abstract}

Keywords Job stress $\cdot$ Homeworking $\cdot$ COVID-19 $\cdot$ University staff members $\cdot$ Egypt

\section{Introduction}

COVID-19 became a pandemic at the beginning of 2020, affecting many countries worldwide. Many measures have been implemented to reduce its spread, the most significant of which was remote home working, which kept people at home and socially separated (Coccia 2020b; Spagnoli and Molinaro 2020).

Following this public health disaster, quarantine and lockdown measures have been implemented globally. These measures can cause a variety of psychological issues, including

Responsible Editor: Lotfi Aleya

Heba Khodary Allam

hebakhodaryallam@yahoo.com; Hebaallam81@gmail.com

1 Public Health and Community Medicine Department, Faculty of Medicine, Menoufia University, Shebin Al-Kom, Menoufia, Egypt increased stress and decreased emotional well-being (Coccia 2021b; Sica et al. 2021).

Many factors may contribute to fear and stress following COVID-19, including not only the direct impact on people's health, but also fears for unemployment due to COVID-19related restrictions, economic difficulties, and concerns about one's health. These stressors and concerns may result in a lower quality of life and negative coping strategies especially after the COVID-19 lockdown (Achterberg et al. 2020; van Ballegooijen et al. 2021).

Over the past few years, various information and communication technologies (ICTs) such as television, mobile phones, the internet, satellite systems, and computer technologies have changed daily. Education, health, the environment, culture, art, and entertainment are all affected by these changes Hoffman et al. (2004). As a result, the majority of the population is struggling to keep up with rapid technological advancements. Change is an unavoidable part of life, and everyone treats it differently. The ICTs have a dual effect 
(Ayyagari and Purvis 2011; Hoffman et al. 2004; Liaw 2002). Whereas the use of ICTs has made substantial productivity gains, creativity, and organizational efficiency, their negative impact should not be ignored on organizations and staff. Organizational culture has become a major source of stress for today's workforce as a result of disruptions in business processes, employee duties, and roles caused by ICTs (Rowden and Conine 2005).

Stress is defined as a mental and physical situation that influences an individual's health, work, and quality of life, with a focus on work-related stress that deprives workers of work satisfaction and quality of life. Technostress is defined as modern disorders of adaptation resulting from a lack of safe handling of new technologies. It is driven by technological tasks like planning meetings, business plans, and concern over time limits for work (Choudhury 2013).

ICT is not the only cause of technostress; many other factors contribute to the development of this stress. Many organizations make the use of ICT one of their primary requirements Tarafdar et al. (2010a, 2010b), as do coworkers, who frequently have an impact on individuals' use of ICT (Avanzi et al. 2018). Technostress caused by misfits between teachers and different aspects of the university setting may influence university teachers' performance negatively, leading to job burnout and even plans to leave the profession (Al-Fudail and Peterson 2004; Ragu-Nathan et al. 2008; Pignata et al. 2016). This stress may manifest itself in both physical and psychological symptoms, and this has been reported by researchers in the computer science, health, and accounting fields (Sami and Pangannaiah 2006). This stress can cause an increase in blood pressure and heart rate, as well as muscle tension, such as a clenched jaw and increased skin conductance. These various symptoms shed light on the physical effects of ICT on users, the presence of which can indicate the presence of technostress. Technostress psychological symptoms include the inability to focus on a single issue, increased irritability, and a sense of loss of control. Technostress also has an impact on employee job satisfaction and commitment, as well as organizational outcomes (Sami and Pangannaiah 2006).

To the best of our knowledge, there is a scarcity of studies on technostress among Egyptian university staff members. Thus, the purpose of this research was to investigate the impact of rapid technological development, particularly in the field of education, on Egyptian university faculty members.

\section{Participants and methods}

\section{Sample and data}

A cross-sectional study was conducted from the first of December 2020 to the end of February 2021 on a probability sample of Egyptian university academic staff members from Menoufia University. The study included staff members who are affiliated with practical and/or theoretical colleges and fulfill the inclusion criteria. A multistage random sample was used to select practical and theoretical colleges from Menoufia University, then the second stage to select the departments in each selected college, and finally staff members were chosen from each selected department by simple random sampling technique.

The sample size was calculated using the EPI $7^{\mathrm{TM}}$ info program (Dean 1999) with a 95\% confidence interval, a 5\% margin of error, and a $10 \%$ prevalence of technostress among university academic staff (KM 2017). The minimum representative sample size was estimated to be 138 , but this was increased to 150 to account for the non-response rate. A total number of 142 staff members responded, for a $94.7 \%$ response rate.

The criteria for inclusion were Egyptian staff members who are affiliated to the selected departments of Menoufia University for 3 years or more, have good English language skills, and agreed to participate.

Subjects with hormonal disorders such as Cushing syndrome or Addisonian disease, subjects on steroid therapy, females taking oral contraceptives, and subjects with known psychological disorders that could influence the results of the technostress subscales were excluded from the study.

\section{Measures of variables}

All participants were subjected to the following:

1- A predesigned self-administered questionnaire that included two main parts:

The first part included:

Sociodemographic data such as age (in years), gender, residence, college specialty (practical or theoretical), and academic grade.

Questions about the presence of modern computers, good WiFi in the virtual work environment, and attendance at training ICT workshops. Modern computers were considered highly efficient computers with windows 7 or 10 and core i3 or higher. Good WiFi was considered to be a continuous presence of online access at or above $25 \mathrm{Mbps}$.

The second part included:

The survey tool is an adapted version of the technostress questionnaire that was developed by Tarfadar and his colleagues in the English language (Tarafdar et al. 2010a). It has three dimensions: (1) techno-overload, the feeling of increased workload due to ICTs (four items); (2) techno-invasion, the feeling of work entering into other areas of life due to ICTs leading to higher levels of family-to-work conflict (three items); and (3) techno-complexity, refers to the user's lack of confidence in using new technologies (four items). Responses 
to the statements were given on a five-point Likert scale ranging from zero (strongly disagree) to four (strongly agree).

Validity and reliability of the three domains (techno-overload, techno-invasion, and techno-complexity) were tested by Ragu-Nathan and his colleagues (Ragu-Nathan et al. 2008) where they found it to be $0.82,0.80$, and 0.77 for each domain respectively that indicated internal consistency of the scale.

2- Blood cortisol level measurement by Cobas e411 immunoassay analyzer (Roche Diagnostics, Mannheim, Germany). Venous blood samples were withdrawn from each participant at a fixed time of the day (9-12 am), to overcome diurnal variation of the cortisol level.

\section{Data analysis}

Data were tested for normality with the Wilks Shapiro test. The Student's t-test was used to compare quantitative variables of normally distributed data, while Mann Whitney's test was used for not normally distributed ones. Pearson correlation was used to test the correlation between two continuous normally distributed variables, while Spearman correlation was used for not normally distributed ones. Multiple linear regressions were used to test the association between multiple possible risk factors and each component of the technical stress. Two-sided P-value of $<0.05$ was considered statistically significant. All the analyses were done using SPSS V. 23 (SPSS Inc. Released 2015. IBM SPSS statistics for windows, version 23.0, Armonk, NY: IBM Corp.).

\section{Results}

The study included 142 participants with full valid questionnaires. Their mean age was $36.32 \pm 6.41$ years (ranging from 25.0 to 60.0 ). Fifty-three percent ( 75 participants) were males, $64.1 \%$ were of rural residence, $52.1 \%$ were working in practical colleges, $60.6 \%$ were lecturers or higher, $54.9 \%$ had training workshops/courses, $78.2 \%$ had good $\mathrm{WiFi}$, and $85.9 \%$ had modern computers (see Table 1). Their mean cortisol level was $15.61 \pm 7.07 \mathrm{mcg} / \mathrm{dl}$ (ranging from 6.0 to $29.0 \mathrm{mcg} / \mathrm{dl}$ ).

Among the entire participants, the mean score $( \pm \mathrm{SD})$ of work overload was $9.45( \pm 2.92)$ out of 15 , the mean invasion score was $6.61( \pm 2.76)$ out of 12 , and the mean complexity score was $12.47( \pm 4.20)$ out of 20.

Female participants, participants who were lecturers or higher grades, and participants who did not have good WiFi or modern computers had significantly higher mean overload, invasion, and complexity than males or participants who were teaching assistants or up (P-value $<0.001$ for each).

Participants who are living in rural areas had a significantly higher overload and complexity scores than participants living in urban areas (P-value 0.002 and 0.001 , respectively), while participants working in practical colleges had significantly
Table 1 Sociodemographic characters of the participants $(n=142)$

\begin{tabular}{ll}
\hline Character & No. $(\%)$ \\
\hline Age & \\
Mean \pm SD & $36.32 \pm 6.41$ \\
Range & $25.0-60.0$ \\
Gender & \\
Male & $75(52.8)$ \\
Female & $67(47.2)$ \\
Residence & \\
Urban & $51(35.9)$ \\
Rural & $91(64.1)$ \\
Work type & \\
Theoretical & $68(47.9)$ \\
Practical & $74(52.1)$ \\
Academic degree & \\
Up to ass. lecturer & $56(39.4)$ \\
Lecturer and higher & $86(60.6)$ \\
Training workshops & $78(54.9)$ \\
Good WiFi & $111(78.2)$ \\
Modern computers & $122(85.9)$ \\
Cortisol (mcg/dl) & $15.61 \pm 7.07$ \\
Mean \pm SD & $6.0-29.0$ \\
Range &
\end{tabular}

higher mean invasion than participants in theoretical ones (P-value 0.004). Participants who did not attend training had significantly higher mean overload, invasion, and complexity than participants who had training (P-value 0.007, 0.021, $<0.001$ ) (see Table 2).

Age had a significantly significant positive correlation with all three aspects of the technostress scale $(\mathrm{P}<0.001$ for each) (Fig. 1).

The multivariate linear regression model showed that overload was significantly related to female gender and work environment with poor WiFi (P-value $<0.001$ and 0.002 , respectively). The invasion was significantly related to the female gender, theoretical colleges, being lecturer or higher, and poor WiFi (P-value 0.001, 0.023, 0.030, and 0.002, respectively), while complexity was significantly related to the female gender, rural residence, no training, poor $\mathrm{WiFi}$, and absence of modern computers (P-value $<0.001,0.014,<0.001,<0.001$, and 0.001 , respectively) (Table 3 ). The three models were statistically significant $\left(\mathrm{P}<0.001\right.$ for each). The adjusted $\mathrm{R}^{2}$ was $0.482,0.362$, and 0.705 for overload, invasion, and complexity, respectively.

Blood cortisol level was found to be higher among participants with higher scores of the technostress subscales. It was significantly correlated with overload and complexity scores (P-value $=0.001$ and $<0.001$, respectively) (Fig. 2). 
Table 2 Mean values of technical stress component with different risk factors

\begin{tabular}{|c|c|c|c|}
\hline Character & $\begin{array}{l}\text { Overload* } \\
\text { Mean } \pm \text { SD }\end{array}$ & $\begin{array}{l}\text { Invasion** } \\
\text { Mean } \pm \text { SD }\end{array}$ & $\begin{array}{l}\text { Complexity*** } \\
\text { Mean } \pm \text { SD }\end{array}$ \\
\hline \multicolumn{4}{|l|}{ Gender } \\
\hline Male & $7.65 \pm 2.23$ & $5.37 \pm 2.09$ & $9.76 \pm 2.71$ \\
\hline Female & $11.46 \pm 2.21$ & $8.01 \pm 2.78$ & $15.52 \pm 3.42$ \\
\hline P-value & $<0.001$ & $<0.001$ & $<0.001$ \\
\hline \multicolumn{4}{|l|}{ Residence } \\
\hline Urban & $8.52 \pm 2.41$ & $6.01 \pm 2.40$ & $10.78 \pm 3.64$ \\
\hline Rural & $9.96 \pm 3.07$ & $6.95 \pm 2.91$ & $13.42 \pm 4.21$ \\
\hline P-value & 0.002 & 0.109 & 0.001 \\
\hline \multicolumn{4}{|l|}{ Work type } \\
\hline Practical & $9.16 \pm 2.93$ & $5.95 \pm 2.69$ & $11.91 \pm 4.04$ \\
\hline Theoretical & $9.71 \pm 2.92$ & $7.22 \pm 2.71$ & $13.00 \pm 4.30$ \\
\hline P-value & 0.235 & 0.004 & 0.142 \\
\hline \multicolumn{4}{|l|}{ Degree } \\
\hline Up to ass. lecturer & $8.16 \pm 2.57$ & $5.25 \pm 2.05$ & $10.00 \pm 2.97$ \\
\hline Lecturer or higher & $10.29 \pm 2.84$ & $7.51 \pm 2.81$ & $14.09 \pm 4.10$ \\
\hline P-value & $<0.001$ & $<0.001$ & $<0.001$ \\
\hline \multicolumn{4}{|l|}{ Training } \\
\hline No & $10.17 \pm 3.04$ & $7.20 \pm 2.79$ & $14.60 \pm 3.84$ \\
\hline Yes & $8.85 \pm 2.70$ & $6.14 \pm 2.67$ & $10.73 \pm 3.66$ \\
\hline P-value & 0.007 & 0.021 & $<0.001$ \\
\hline \multicolumn{4}{|l|}{ Good WiFi } \\
\hline No & $12.09 \pm 2.03$ & $9.12 \pm 2.37$ & $17.16 \pm 2.64$ \\
\hline Yes & $8.71 \pm 2.70$ & $5.91 \pm 2.45$ & $11.17 \pm 3.58$ \\
\hline P-value & $<0.001$ & $<0.001$ & $<0.001$ \\
\hline \multicolumn{4}{|l|}{ Modern computers } \\
\hline No & $12.15 \pm 1.89$ & $9.10 \pm 2.22$ & $18.05 \pm 1.43$ \\
\hline Yes & $9.00 \pm 2.82$ & $6.21 \pm 2.64$ & $11.56 \pm 3.78$ \\
\hline P-value & $<0.001$ & $<0.001$ & $<0.001$ \\
\hline
\end{tabular}

*Overload: the feeling of increased workload due to ICTs

**Invasion: the feeling of work entering into other areas of life due to ICTs leading to higher levels of family-to-work conflict

***Complexity: refers to the user's lack of confidence in using new technologies

\section{Discussion}

COVID-19's global lockdown had impacted everyone's quality of life by disrupting their daily routines. Students, as an example, had higher levels of "perceived academic stress" and higher depressive symptoms (De Man et al. 2021; Vyas and Butakhieo 2020). Policymakers should support appropriate long-run strategies that prevent the negative effects of infectious diseases especially those causing pandemics as COVID-19 on public health, the economy, and society (Coccia 2020a, 2021a).

Employees who work from virtual offices can do their work anywhere at any time, which may blur the lines between work and home. As a result, workplace stress has been allowed to spread from traditional offices to virtual offices, potentially leading to fewer social interactions and poor communication (KM 2017; Stich 2020)

Participants in this study reported moderate to high levels of the technostress questionnaire's various subscales. Job overload had a mean score of $9 / 15$, which was $60 \%$ of the maximum overload score, followed by work complexity ( $57 \%$ of the maximum score) and invasion (50\% of the max. score). Remote working was found to be strongly associated with the three technostress subscales by Molino and his colleagues. Work-family conflict on the one hand and work overload on the three technostress subscales on the other were found to have a strong positive association in their analysis. They also discovered a significant positive relationship between behavioral stress and workload, as well as technostress subscales and work-family conflict (Molino et al. 2020). Moretti et al. (2020) have reported that the home environment appears to be inappropriate, with an increased risk of mental health issues.

The higher levels of stress among employees who use ICT were explained by the constant availability of the individual, predicting quicker and better work Ayyagari and Purvis (2011).

Technostress caused by virtual work is multifactorial. The induced technostress was caused by both personal and environmental risk factors. The multivariate analysis of our findings revealed that gender and WiFi quality both contributed significantly to all subscales of technostress. Other risk factors may differ depending on the subscale.

In our study, senior participants with higher academic degrees were found to be significantly associated with higher levels of the three domains of technostress. In the study done by Orlando (2014), old-age teachers who have taken years in establishing their teaching practices suffered greatly to change them than the younger teachers. Also, Tsertsidis et al. (2019) stated that older people have more negative attitudes towards the use of new technologies and feel less competent. Sahin and Coklar found that technostress increase with age (Şahin and Çoklar 2009). According to a meta-analysis by Hauk et al. (2018), older adults have more difficulty using technology than younger adults, especially with techno-overload and techno-complexity, which necessitate a diverse set of cognitive abilities and physical condition.

Female participants in this study reported higher technostress levels than males. This was also reported by Efilti and Naci Çoklar (2019) and Thomée et al. (2012) who found that women experience higher levels of anxiety and exhaustion than men in the use of ITC's. Margetić et al. (2021) found that emotional distress during COVID-19 pandemic was more intensive in women and younger participants.

Liaw's study also indicated that males had more positive perceptions towards computers and Web technologies than females (Liaw 2002). Broos survey revealed that males had less computer anxiety than females as they use computers for longer periods so they show less computer anxiety (Broos 
Fig. 1 Scatter plot of age correlation with technical stress components

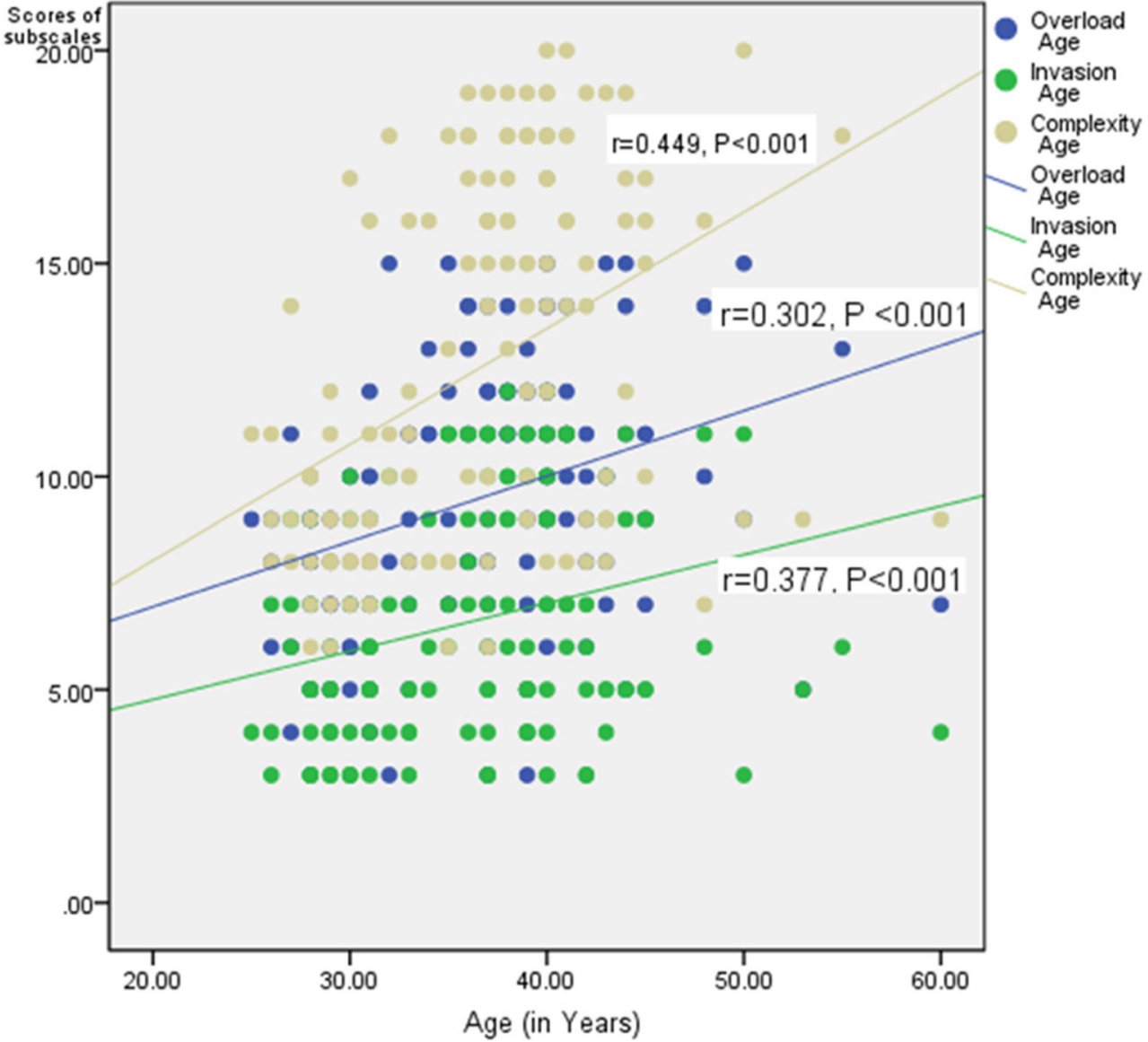

2005). Females' high technostress in our sample could be due to the fact that they have to care for their children and families when working from home during the lockdown, which adds to their burden.

Table 3 Multivariate regression of possible risk factors of technical stress components

\begin{tabular}{|c|c|c|c|c|c|c|}
\hline \multirow[t]{2}{*}{ Variables } & \multicolumn{2}{|c|}{ Overload } & \multicolumn{2}{|c|}{ Invasion } & \multicolumn{2}{|c|}{ Complexity } \\
\hline & Beta & $\mathrm{P}$ & Beta & $\mathrm{P}$ & Beta & $\mathrm{P}$ \\
\hline Age & 0.145 & 0.117 & -0.066 & 0.523 & 0.129 & 0.066 \\
\hline Gender & 0.495 & $<0.001$ & 0.270 & 0.001 & 0.391 & $<0.001$ \\
\hline Residence & -0.076 & 0.225 & -0.040 & 0.567 & -0.118 & 0.014 \\
\hline Work type & 0.023 & 0.706 & 0.157 & 0.023 & 0.021 & 0.655 \\
\hline Degree & -0.027 & 0.782 & 0.233 & 0.030 & 0.080 & 0.273 \\
\hline Training & 0.013 & 0.841 & 0.035 & 0.628 & -0.206 & $<0.001$ \\
\hline Good WiFi & -0.231 & 0.002 & -0.259 & 0.002 & -0.214 & $<0.001$ \\
\hline Modern computers & -0.058 & 0.408 & -0.090 & 0.247 & -0.187 & 0.001 \\
\hline $\mathrm{F}$ & 17.42 & $<0.001$ & 11.01 & $<0.001$ & 43.02 & $<0.001$ \\
\hline $\mathrm{R}^{2}$ adj & 0.482 & & 0.362 & & 0.705 & \\
\hline
\end{tabular}

Even though industrialized areas in Italy had substantially higher COVID-19 infection and death rates (Coccia, 2021), participants in our study who lived in rural areas had higher levels of technostress. This may be explained by the rural areas' lack of resources. Poor WiFi and recurrent interruptions of internet access will make it difficult to complete necessary tasks and create a stressful virtual work environment (Chuang et al. 2015).

Poor WiFi connection was significantly associated with higher levels of technostress. KM (2017) stated that a slow internet network was considered a factor contributing to technostress.

Participants in practical colleges experienced significantly higher mean invasion technological stress than those in theoretical colleges. According to Mishra et al. (2020), because of the need for equation manipulation and laboratories, practical subjects have traditionally been difficult to teach online. This may also be due to educators' negative attitudes toward new technologies and tools. Educators also have limited time and patience to address minor technical issues throughout the process of adjustment to new tools.

Participants who did not attend technological training workshops had significantly higher mean overload, invasion, and complexity than participants who had. This was in agreement 
Fig. 2 Scatter plot of cortisol level $(\mathrm{mcg} / \mathrm{dl})$ association with technical stress components

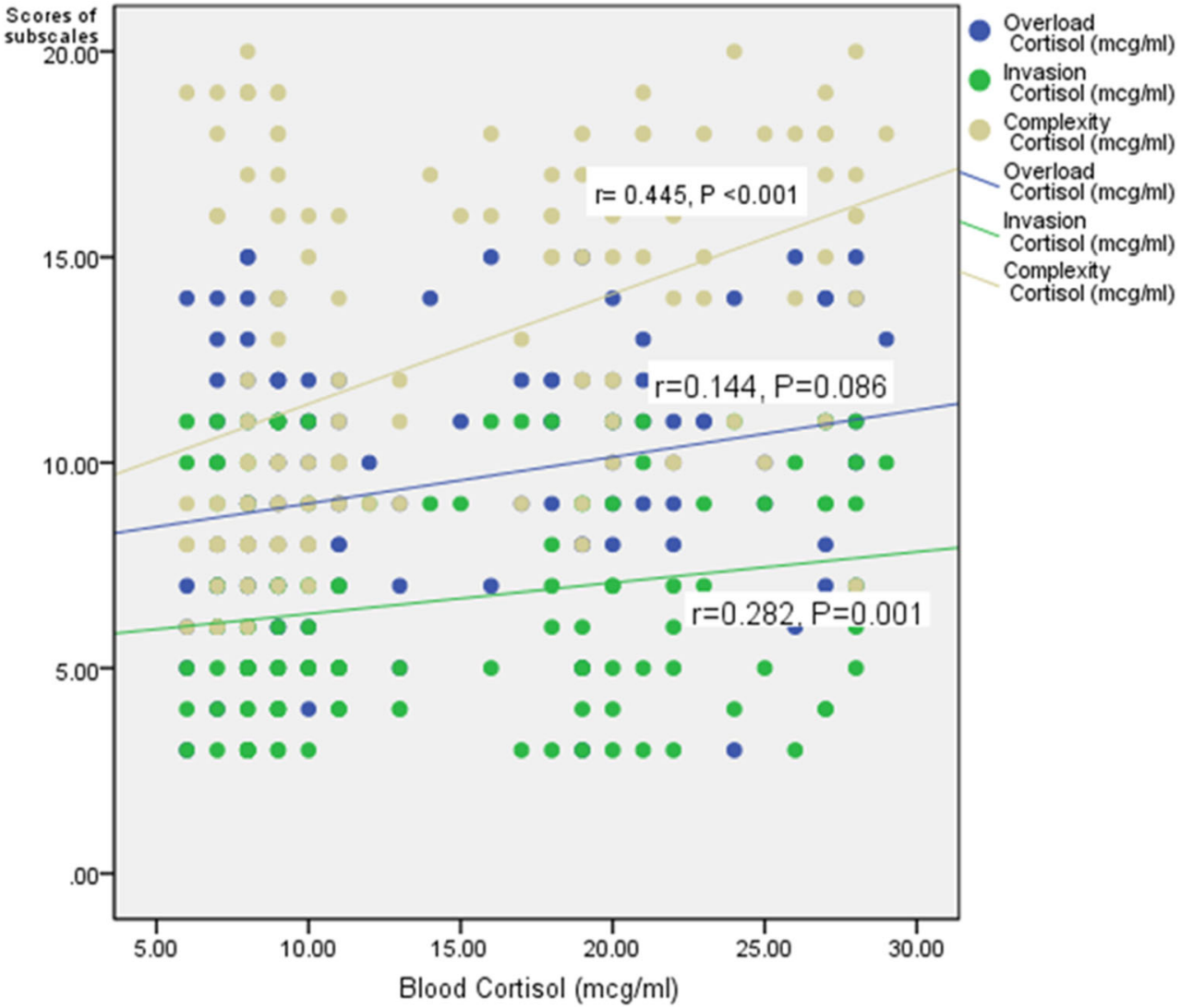

with Tarafdar et al. $(2007,2010 \mathrm{~b})$ who indicated that users with high levels of computer knowledge could avoid technostress to a larger degree. Gaither Shepherd (n.d.) concluded that computer skills influenced technostress levels.

University support was considered an essential component of preparing teachers to use ICT effectively (Luchman and González-Morales 2013). According to Shedletsky and Aitken (2001), teachers frequently avoid university supplies such as professional development workshops and technical seminars.

K.M (2017) stated that there was no statistically significant relationship between technostress and respondents' age group, gender, or attendance at technology-related training.

According to our study, cortisol level was significantly higher with overload and complexity domains of technostress (P-value 0.001 and $<0.001$, respectively). Riedl et al. (2012) found that cortisol levels increased significantly as a result of system breakdown in a human-computer interaction task. Also Riedl et al. (2012) revealed significantly elevated cortisol levels due to human interaction with ICT.

\section{Conclusion}

Technostress was prevalent among university staff members. Female participants, being lecturers or higher profession, and not having rapid $\mathrm{WiFi}$ or modern computers were predictors of technostress. Age had a significant positive correlation with all three aspects of the technostress scale (overload, invasion, complexity). Cortisol level was significantly higher with overload and complexity.

Cross-sectional design was a limitation to our study as longitudinal studies will be needed to determine the causal relationship among these variables.

Another limitation was the negligence of the personality traits and considering the sociodemographic factors as the only factors that affect the level of technostress. So, it is critical to investigate and explain the effects of shorter/longer periods of lockdown on staff members' mental health to design effective containment measures aimed at reducing and/or containing the impact of potential COVID-19 waves and future epidemics similar to the COVID-19 in communities, as well as not affecting the mental health and well-being of staff members.

To ensure a technostress free work environment, the following measures should be considered:

- By staff members: Set clear boundaries between working and non-working hours, create a separate working area in your home, and stick to a strict schedule.

- By the administration: Provide training courses and a responsive IT team and assign the right job to the right people, and workers should be inspired and encouraged by motivational messages. 
- By the government: Organizations must use behavioral monitoring techniques to track any signs of technostress. This is especially critical during periods of crisis, as targeted actions can be used to implement immediate corrective measures, preventing harmful behavior patterns. Further research should take personality traits into account.

Acknowledgements The authors would like to express their gratitude to all the staff who agreed to participate in this study.

Author contribution Dr. Hala Marawan Gabr has conceived the idea, Dr. Shaimaa Sherif Soliman has conducted the statistical analysis, Dr. Heba Khodary Allam edited the manuscript and do reference check. Dr. Shaimaa Yaihya Abd El Raouf has written the draft of the manuscript. All the authors contributed to the design and implementation of the research, collection of data, and the revision of the manuscript.

Data availability Data are available upon reasonable request.

\section{Declarations}

Ethical considerations Institutional Review Board of Faculty of Medicine, Menoufia University, Egypt, had ethically approved the study before data collection.

Consent to participate All responders have participated voluntarily after written informed consent (to participate and publish) had been signed. The participants' data were kept confidential and were used only for research purposes.

Consent for publication The authors assign publication rights to the journal, and we guarantee that this contribution is unique and that we have full authority to make this grant.

Competing interests The authors declare no competing interests.

\section{References}

Achterberg M, Dobbelaar S, Boer OD, Crone E (2020) Perceived stress as mediator for longitudinal effects of the COVID-19 lockdown on wellbeing of parents and children. Center for Open Science. https:// doi.org/10.31234/osf.io/pj3sg

Al-Fudail M, Peterson D (2004) TechnoStress; The disease of the fourth wave. PsycEXTRA Dataset

Avanzi L, Fraccaroli F, Castelli L et al (2018) How to mobilize social support against workload and burnout: The role of organizational identification. Teach Educ 69:154-67

Ayyagari G, Purvis (2011) Technostress: technological antecedents and implications. MIS Q 35(4):831. https://doi.org/10.2307/41409963

Broos A (2005) Gender and information and communication technologies (ICT) anxiety: male self-assurance and female hesitation. CyberPsychology \& Behavior 8(1):21-31. https://doi.org/10.1089/ cpb.2005.8.21

Choudhury K (2013) Managing workplace stress. Springer India. https:// doi.org/10.1007/978-81-322-0683-5

Chuang A, Shen C-T, Judge TA (2015) Development of a multidimensional instrument of person-environment fit: the perceived person- environment fit scale (PPEFS). Appl Psychol 65(1):66-98. https:// doi.org/10.1111/apps.12036

Coccia M (2020a) The effects of atmospheric stability with low wind speed and of air pollution on the accelerated transmission dynamics of COVID-19. Int J Environ Stud 78(1):1-27. https://doi.org/10. 1080/00207233.2020.1802937

Coccia M (2020b) An index to quantify environmental risk of exposure to future epidemics of the COVID-19 and similar viral agents: theory and practice. Environ Res 191:110155. https://doi.org/10.1016/j. envres.2020.110155

Coccia M (2021a) Effects of the spread of COVID-19 on public health of polluted cities: results of the first wave for explaining the dejà vu in the second wave of COVID-19 pandemic and epidemics of future vital agents. Environ Sci Pollut Res 28(15):19147-19154. https:// doi.org/10.1007/s11356-020-11662-7

Coccia M (2021b) The relation between length of lockdown, numbers of infected people and deaths of Covid-19, and economic growth of countries: lessons learned to cope with future pandemics similar to Covid-19 and to constrain the deterioration of economic system. Sci Total Environ 775:145801. https://doi.org/10.1016/j.scitotenv.2021. 145801

De Man J, Buffel V, van de Velde S, Bracke P, Van Hal GF, Wouters E (2021) Disentangling depression in Belgian higher education students amidst the first COVID-19 lockdown (April-May 2020). Archives of Public Health 79(1):3. https://doi.org/10.1186/s13690020-00522-y

Dean AG (1999) Epi Info and Epi Map. Journal of Public Health Management and Practice 5(4):54-56. https://doi.org/10.1097/ 00124784-199907000-00011

Efilti E, Naci Çoklar A (2019) Teachers' technostress levels as an indicator of their psychological capital levels. Univ J Educ Res 7(2): 413-421. https://doi.org/10.13189/ujer.2019.070214

Gaither Shepherd SS (n.d.) Computer skills, technostress, and gender in higher education. In Online and distance learning IGI Global:30113019. https://doi.org/10.4018/978-1-59904-935-9.ch245

Hauk N, Hüffmeier J, Krumm S (2018) Ready to be a silver surfer? A Meta-analysis on the relationship between chronological age and technology acceptance. Comput Hum Behav 84:304-319. https:// doi.org/10.1016/j.chb.2018.01.020

Hoffman DL, Novak TP, Venkatesh A (2004) Has the Internet become indispensable? Commun ACM 47(7):37-42. https://doi.org/10. $1145 / 1005817.1005818$

KM O (2017) Prevalence and correlates of technostress among academic staff at the University of Jos, Nigeria. Journal of Medical Science And Clinical Research 5(3):18616-18624. https://doi.org/10.18535/ $\mathrm{jmscr} / \mathrm{v} 5 \mathrm{i} 3.57$

Liaw S-S (2002) Understanding user perceptions of world-wide web environments. J Comput Assist Learn 18(2):137-148. https://doi. org/10.1046/j.0266-4909.2001.00221.x

Luchman JN, González-Morales MG (2013) Demands, control, and support: a meta-analytic review of work characteristics interrelationships. J Occup Health Psychol 18(1):37-52. https://doi.org/10. 1037/a0030541

Margetić B, Peraica T, Stojanović K, Ivanec D (2021) Predictors of emotional distress during the COVID-19 pandemic; a Croatian study. Personal Individ Differ 175:110691. https://doi.org/10.1016/j.paid. 2021.110691

Mishra L, Gupta T, Shree A (2020) Online teaching-learning in higher education during lockdown period of COVID-19 pandemic. International Journal of Educational Research Open 1:100012. https://doi.org/10.1016/j.ijedro.2020.100012

Molino M, Ingusci E, Signore F, Manuti A, Giancaspro ML, Russo V, Zito M, Cortese CG (2020) Wellbeing costs of technology use during Covid-19 remote working: an investigation using the Italian translation of the technostress creators scale. Sustainability 12(15): 5911. https://doi.org/10.3390/su12155911 
Moretti A, Menna F, Aulicino M, Paoletta M, Liguori S, Iolascon G (2020) Characterization of home working population during COVID-19 emergency: a cross-sectional analysis. Int J Environ Res Public Health 17(17):6284. https://doi.org/10.3390/ ijerph17176284

Orlando J (2014) Veteran teachers and technology: change fatigue and knowledge insecurity influence practice. Teachers and Teaching 20(4):427-439. https://doi.org/10.1080/13540602.2014.881644

Pignata S, Winefield AH, Boyd Provis C, CM (2016) Awareness of stress-reduction interventions on work attitudes: the impact of tenure and staff group in Australian Universities. Front Psychol 7:1225

Ragu-Nathan TS, Tarafdar M, Ragu-Nathan BS, Tu Q (2008) The consequences of technostress for end users in organizations: conceptual development and empirical validation. Inf Syst Res 19(4):417-433. https://doi.org/10.1287/isre.1070.0165

Riedl R (2012) On the biology of technostress. ACM SIGMIS Database: The DATABASE for Advances in Information Systems 44(1):18 55. https://doi.org/10.1145/2436239.2436242

Riedl R, Kindermann H, Auinger A, Javor A (2012) Technostress from a neurobiological perspective. Bus Inf Syst Eng 4(2):61-69. https:// doi.org/10.1007/s12599-012-0207-7

Rowden RW, Conine CT (2005) The impact of workplace learning on job satisfaction in small US commercial banks. J Work Learn 17(4): 215-230. https://doi.org/10.1108/13665620510597176

Şahin YL, Çoklar AN (2009) Social networking users' views on technology and the determination of technostress levels. Procedia Soc Behav Sci 1(1):1437-1442. https://doi.org/10.1016/j.sbspro.2009. 01.253

Sami LK, Pangannaiah NB (2006) "Technostress" A literature survey on the effect of information technology on library users. Libr Rev 55(7):429-439. https://doi.org/10.1108/00242530610682146

Shedletsky LJ, Aitken JE (2001) The paradoxes of online academic work. Commun Educ 50(3):206-217. https://doi.org/10.1080/ 03634520109379248

Sica C, Perkins ER, Latzman RD, Caudek C, Colpizzi I, Bottesi G, Caruso M, Giulini P, Cerea S, Patrick CJ (2021) Psychopathy and COVID-19: triarchic model traits as predictors of disease-risk perceptions and emotional well-being during a global pandemic. Personal Individ Differ 176:110770. https://doi.org/10.1016/j.paid. 2021.110770
Spagnoli P, Molinaro D (2020) Negative (workaholic) emotions and emotional exhaustion: might job autonomy have played a strategic role in workers with responsibility during the Covid-19 Crisis Lockdown? Behav Sci 10(12):192. https://doi.org/10.3390/ bs10120192

Stich JF (2020) A review of workplace stress in the virtual office. In Intelligent Buildings International Taylor and Francis Ltd. 12(3): 208-220. https://doi.org/10.1080/17508975.2020.1759023

Tarafdar M, Tu Q, Ragu-Nathan BS, Ragu-Nathan TS (2007) The impact of technostress on role stress and productivity. J Manag Inf Syst 24(1):301-328. https://doi.org/10.2753/mis0742-1222240109

Tarafdar M, Tu Q, Ragu-Nathan T (2010a) Technostress questionnaire. In PsycTESTS Dataset American Psychological Association (APA). https://doi.org/10.1037/t53850-000

Tarafdar M, Tu Q, Ragu-Nathan TS (2010b) Impact of technostress on end-user satisfaction and performance. J Manag Inf Syst 27(3):303334. https://doi.org/10.2753/mis0742-1222270311

Thomée S, Härenstam A, Hagberg M (2012) Computer use and stress, sleep disturbances, and symptoms of depression among young adults - a prospective cohort study. BMC Psychiatry 12(1):176. https://doi.org/10.1186/1471-244X-12-176

Tsertsidis A, Kolkowska E, Hedström K (2019) Factors influencing seniors' acceptance of technology for ageing in place in the postimplementation stage: a literature review. In International Journal of Medical Informatics Elsevier Ireland Ltd. 129:324-333. https:// doi.org/10.1016/j.ijmedinf.2019.06.027

van Ballegooijen H, Goossens L, Bruin RH, Michels R, Krol M (2021) Concerns, quality of life, access to care and productivity of the general population during the first 8 weeks of the coronavirus lockdown in Belgium and the Netherlands. BMC Health Serv Res 21(1): 227. https://doi.org/10.1186/s12913-021-06240-7

Vyas L, Butakhieo N (2020) The impact of working from home during COVID-19 on work and life domains: an exploratory study on Hong Kong. https://doi.org/10.1080/25741292.2020.1863560

Publisher's note Springer Nature remains neutral with regard to jurisdictional claims in published maps and institutional affiliations. 